\title{
Introduction to Papers Presented at the Orlo H. Clark Festschrift
}

\author{
Quan-Yang Duh · Electron Kebebew • \\ Wen T. Shen
}

Published online: 30 October 2008

(c) Société Internationale de Chirurgie 2008

On April 4, 2008, a total of 120 past and current colleagues, fellows, and friends of Orlo H. Clark gathered in San Francisco to honor Orlo with a Festschrift. Thirty talks were given over the course of the day, spanning the entire spectrum of clinical and basic science research in endocrine surgery. They all had one thing in common-each speaker had been profoundly influenced by Dr. Clark during the course of his or her career. This issue of the World Journal of Surgery contains manuscripts from some of the talks given at the Orlo H. Clark Festschrift. These manuscripts exemplify his intellectual curiosity, creative problem-solving, dedication to surgical education, and unflagging dedication to improving the understanding, technique, and practice of endocrine surgery. We hope that you enjoy the work presented herein and join us in recognizing and honoring Orlo H. Clark's enormous contributions to the field of endocrine surgery and to our profession as a whole.

Q.-Y. Duh · E. Kebebew $(\square) \cdot$ W. T. Shen

Department of Surgery, University of California at San

Francisco, Third Street and Parnassus Avenue, San Francisco,

CA 94143, USA

e-mail: kebebewe@surgery.ucsf.edu 